\title{
Variation of Carrying Angle With Age, Sex, Height and Special Reference to Side
}

\author{
Sharma K, ${ }^{1}$ Mansur DI, ${ }^{1}$ Khanal K, ${ }^{2}$ Haque $\mathrm{MK}^{1}$
}

\author{
${ }^{1}$ Department of Anatomy \\ ${ }^{2}$ Department of Community Medicine \\ Dhulikhel Hospital - Kathmandu University Hospital \\ Kathmandu University School of Medical Sciences \\ Dhulikhel, Kavre, Nepal
}

Corresponding author

Kalpana Sharma

Department of Anatomy

Dhulikhel Hospital - Kathmandu University Hospital

Kathmandu University School of Medical Sciences

Dhulikhel, Kavre, Nepal

Email: kalpananepal2011@gmail.com

\section{Citation}

Sharma K, Mansur DI, Khanal K, Haque MK. Variation of Carrying Angle With Age, Sex, Height and Special Reference to Side. Kathmandu Univ Med J 2013;44(4):315-318.

\begin{abstract}
Background

The carrying angle is defined as the acute angle made by the median axis of arm and median axis of forearm in full extension and supination. This angle permits the forearms to clear the hips in swinging movements during walking and is important when carrying objects.
\end{abstract}

\section{Objective}

The purpose of this study was to determine the values of carrying angle in both the sexes according to the age group in relation with height and special reference to side.

\section{Methods}

To evaluate the elbow carrying angle in normal children between 5-15 years by a manual goniometer, measurements were performed in 532 children (Male- 335, Female- 197), with the elbow in full extension and forearm in supination. Carrying angle was measured on right and left upper limbs to find out the difference on both the limbs. Their height, ages and sexes are also recorded. Bicipital groove, biceps brachii tendon at its insertion and palmaris longus tendon at the wrist were palpated and marked as anatomical landmarks to demarcate the median axes of arm and forearm respectively.

\section{Results}

The mean carrying angle of male on the left limb was $7.0359^{\circ}$ and the female was $7.8030^{\circ}$ and the mean carrying angle of male on the right limb was $4.5509^{\circ}$ and the female was $4.9545^{\circ}$. We observed the greater carrying angle in non-dominant limb than the dominant limbs. There was significant positive correlation between height of students and carrying angle left $(r=0.0866, p=0.048<0.05)$, negative correlation between height and carrying angle right $(r=-0.082, p=0.058>0.05)$.

\section{Conclusion}

The present study showed that the carrying angle was greater in female than in male and was greater in non-dominant arm than in dominant arm and the carrying angle was not inversely related to the height of the person.

\section{KEY WORDS}

Carrying angle, dominant limb, forearm, non-dominant limb, supination

\section{INTRODUCTION}

The carrying angle is defined as the acute angle made by the median axis of arm and median axis of forearm in full extension and supination. ${ }^{1}$ The angle is neutralized when the forearm is flexed or pronated from extended or supinated position. ${ }^{2}$ This angle permits the forearms to clear the hips in swinging movements during walking and is important when carrying objects. ${ }^{3}$ The carrying angle value and its pathological variations are important in the management of elbow fractures and in the diagnosis of the disease of lateral and medial epicondyles. ${ }^{4}$ It is generally said that carrying angle is greater in females than in males and the difference has been considered to be a secondary sex characteristics. However, some researchers' reported no significant difference in carrying angle of males and females of any age group. ${ }^{5}$ The purpose of this study was to determine the values of carrying angle in both the sexes 
according to the age group in relation with height and special reference to side.

\section{METHODS}

In the present study, total 532 (Male- 335, Female-197) healthy students of Kathmandu University High School, Chaukot and Gyan Jyoti English Boarding School, Banepa were selected. Their ages ranged between $5-15$ years. The carrying angle was measured using the manual goniometer made of flexible clear plastic having both the fixed and movable arms as shown in fig 4. The fixed arm of it could be placed on the median axes of the upper arm, the movable arm adjusted on the median axes of forearm. Bicipital groove, biceps brachii tendon at its insertion and palmaris longus tendon at the wrist were palpated and marked as anatomical landmarks to demarcate the median axes of the arm and the forearm respectively. Carrying angle was measured on right and left limbs to find out the difference on both the limbs. Their height, ages and sexes were also recorded. Height was measured by the measuring tape in the standing, erect, anatomical position from the vertex to hill with bare foot. Height was measured in meters and carrying angle was measured in degrees. Age was recorded by asking the subjects. In the present study fracture limbs were discarded. The data collected were computerized and statistical analysis was done where appropriate.

\section{RESULTS}

An attempt had been made to identify the variation of carrying angle with age (5-15 years) and sex. Variation of carrying angle in dominant and non-dominant limb and its relation with the height of a person were also studied. This study included 532 children, 335 males and 197 females. Children with the fractured limbs were discarded from the study. All children were found to be right hand dominant group.

\section{Different statistics of carrying angle left, carrying angle right with height and sex}

The mean carrying angle of male on the left limb was $7.03^{\circ}$ and the female was $7.80^{\circ}$ (Table 1 ). Here t530 $=-2.363, p$ $=0.018(<0.05)$, so mean carrying angle left between male and female population were significantly different, furthermore, mean carrying angle left of female population was significantly greater $(p=0.009<0.05)$ compared to mean carrying angle left of male population.

The mean carrying angle of male on the right limb was 4.55을 and the female was $4.95^{\circ}$ (Table 1 ). Although mean carrying angle right of female was more compared to male, but this study found no significant difference between them $(\mathrm{t} 530=-1.275, \mathrm{p}=0.203>0.05)$.
Table 1. Different Statistics on Height, Sex, Carrying Angle Left and Carrying Angle Right.

$n=532$

\begin{tabular}{|cccc|}
\hline Sex & $\begin{array}{c}\text { Carrying Angle } \\
\text { Left (Degree) }\end{array}$ & $\begin{array}{c}\text { Carrying An- } \\
\text { gle Right }\end{array}$ & $\begin{array}{c}\text { Height } \\
(\mathbf{m})\end{array}$ \\
\hline Mean & 7.03 & 4.55 & 1.42 \\
\hline Std. Deviation & 3.40 & 3.37 & 0.19 \\
\hline Range & 17.00 & 14.00 & 0.83 \\
\hline Minimum & 0.00 & 0.00 & 1.00 \\
\hline Maximum & 17.00 & 14.00 & 1.83 \\
\hline Mean & 7.80 & $\mathbf{n}=198$ & 1.30 \\
\hline Std. Deviation & 3.95 & 3.78 & 0.15 \\
\hline Range & 19.00 & 20.00 & 0.67 \\
\hline Minimum & 0.00 & 0.00 & 1.01 \\
\hline Maximum & 19.00 & 20.00 & 1.68 \\
\hline
\end{tabular}

Variation of carrying angle in dominant and non-dominant limb

The carrying angle of non-dominant limb (Left upper limb) in both sexes varied from $0^{\circ}$ to $19^{\circ}$ with average of $7.32^{\circ} \pm 3.63^{\circ}$. The carrying angle of dominant limb (Right upper limb) of both sexes varied from $0^{\circ}$ to $20^{\circ}$ with average of $4.70^{\circ} \pm 3.53^{\circ}$ (Table 2). Thus, it was observed that the carrying angle of dominant limb was lesser than nondominant limb.

Table 2. Carrying Angle of Dominant and Non-dominant limbs of Male and Female.

$n=532$

\begin{tabular}{|c|c|c|c|}
\hline & Height (m) & $\begin{array}{l}\text { Carrying Angle } \\
\text { Left } \\
\text { (Degree) }\end{array}$ & $\begin{array}{l}\text { Carrying Angle Right } \\
\text { (Degree) }\end{array}$ \\
\hline Mean & 1.37 & 7.32 & 4.70 \\
\hline
\end{tabular}

\begin{tabular}{|llll|}
\hline $\begin{array}{l}\text { Std. Error } \\
\text { of Mean }\end{array}$ & 0.008 & 0.15 & 0.15 \\
\hline Median & 1.36 & 7.00 & 4.00 \\
\hline Mode & 1.36 & 6.00 & 2.00 \\
\hline $\begin{array}{l}\text { Std. Devia- } \\
\text { tion }\end{array}$ & 0.18 & 3.63 & 3.53 \\
\hline Range & 0.83 & 19.00 & 20.00 \\
\hline Minimum & 1.00 & 0.00 & 0.00 \\
\hline Maximum & 1.83 & 19.00 & 20.00 \\
\hline
\end{tabular}

\section{Relation of carrying angle with height}

Fig 1 and fig 2 are the scatter diagram between height (m) and carrying angle left and right respectively and fig 3 represents scatter diagram between carrying angle left and right.

There was significant positive correlation between height of students and carrying angle left $(r=0.08, p=0.048<0.05)$, negative correlation between height and carrying angle right ( $r=-0.08, p=0.058>0.05$ ) however, there is a significant 


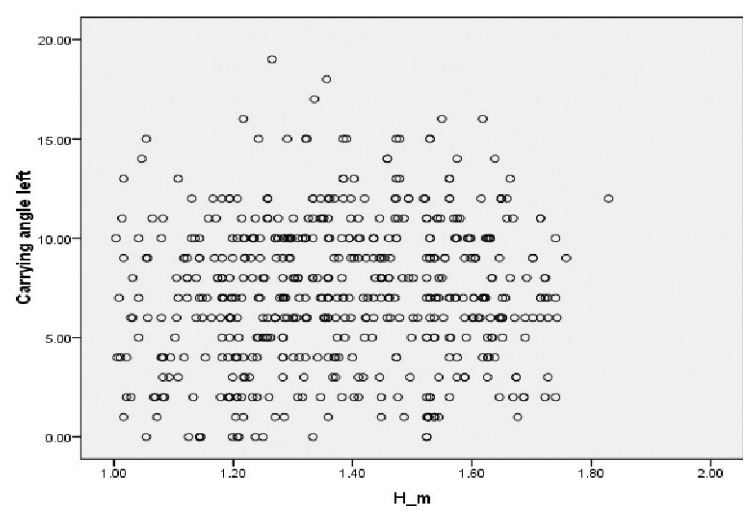

Figure 1. Relation of Carrying Angle Left with Height.

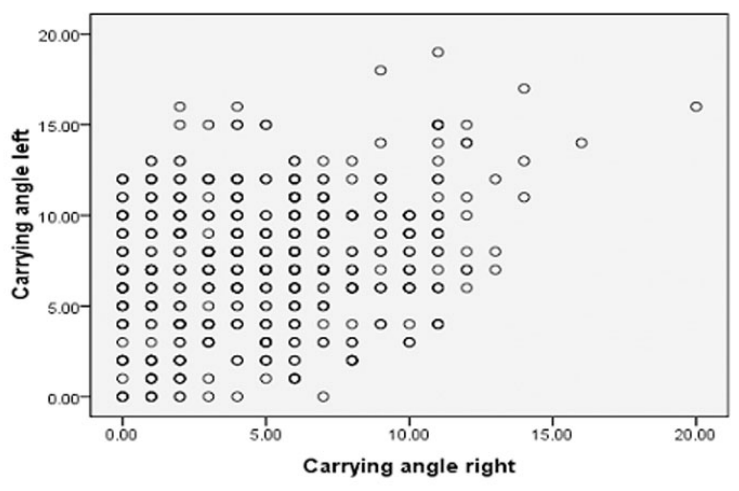

Figure 3. Relation of Carrying Angle Right with Carrying angle Left.

positive correlation between carrying angle left and right $(r=0.273, p=0<0.05)$.

\section{Variation of carrying angle right and left with age}

The minimum carrying angle on the left and right limb was found at the age of 11 and 10 years respectively whereas maximum carrying angle on left and right limb was found at the age of 9 and 14 years respectively (Table 3 ).

Table 5. Variation of Carrying Angle Right and Left with Age.

\begin{tabular}{|lll|}
\hline Minimum Variation & Carrying angle Left & Carrying angle Right \\
\hline Maximum Variation & 4.0821 (11 years) & 3.046 ( 10 years) \\
\hline Maximum Angle & 19 (9 years) & 20 (14 years)
\end{tabular}

\section{DISCUSSION}

Knowledge of the measurement of the elbow carrying angle and of its variations is important when evaluating traumatic elbow injuries in childhood and in adolescence and other elbow disorders that require reconstruction or arthroplasties. ${ }^{6}$ Several authors have attempted to determine the variation of carrying angle with age and sex. Potter was the first to carry out an investigation on variation of carrying angle in male and female. ${ }^{7}$ He observed the greater carrying angle in females than in males. Subsequent measurements were made by Mall. ${ }^{8}$ Since, then different measurements of carrying angle have been performed in a

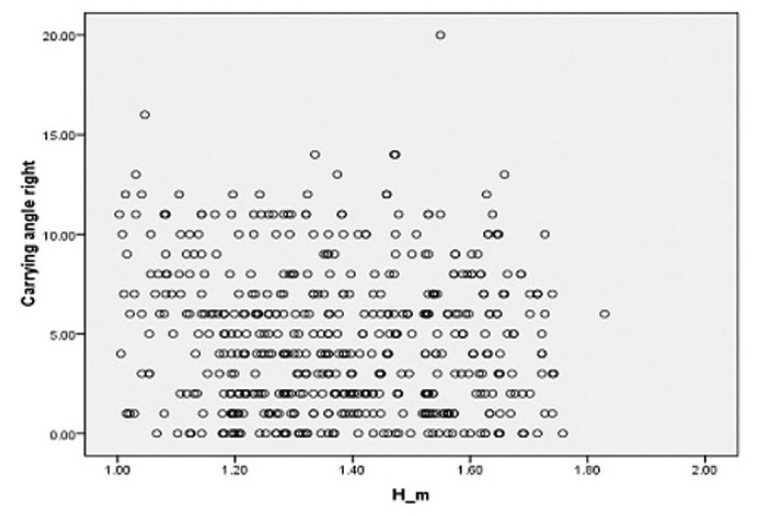

Figure 2. Relation of Carrying Angle Right With Height.

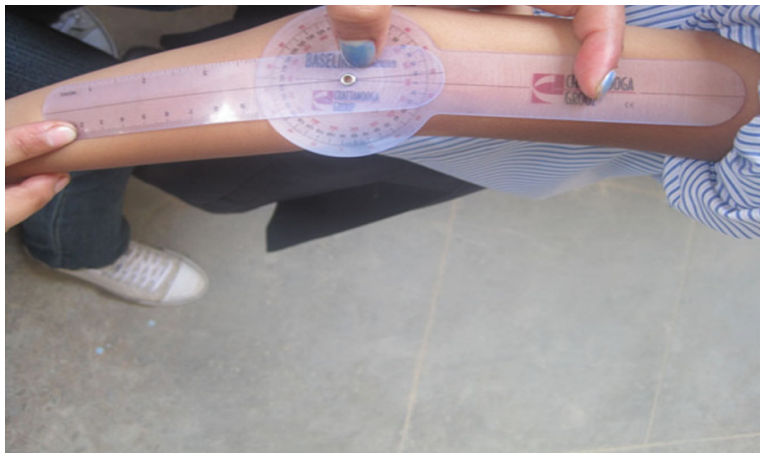

Figure 4. Measurement of Carrying Angle by Using Goniometer.

variety of ways ranging from use of a simple goniometer to some complex radiological procedure. This study intended to determine the variation of carrying angle with age, sex and its relation with height and special reference to side. Many similarities as well as differences were observed as compared to the result obtained by other authors.

In the present study the mean carrying angle of female on the left limb was $7.80^{\circ}$ and of male was $7.03^{\circ}$. Mean carrying angle left between male and female population were significantly different $(\mathrm{t} 530=-2.36, \mathrm{p}=0.01<0.05)$. The mean carrying angle of female on the right limb was 4.95 and the male was 4.55 degrees. Although mean carrying angle right of female was more compared to that of male, but we found no significant difference between them (t530 $=-1.27, p=0.20>0.05$ ). Maria et. al observed the mean carrying angle for women as $12.9 \pm 3.95^{\circ}$ and mean carrying angle for men as $12.39 \pm 3.64^{\circ}$ and the difference was not statistically significant as found in our study on the right limb of both the males and females. Most of the study by different researchers showed that the carrying angle of female was greater than the male which also support our study. ${ }^{4,9-11}$ However, some researchers found no significant difference in carrying angles of males and females of any age group. ${ }^{3,12,13}$

Van et al evaluated the mean carrying angle of $11.6^{\circ} \pm 3.2^{\circ}$ in the male and $16.7^{\circ} \pm 2.6^{\circ}$ in the female subjects. ${ }^{14}$ The finding of the present study was less than that of his study 
because the subjects included in our study were between 5-15 years.

Yilmaz et al recorded the carrying angle in right arm dominant group to be $10.57^{\circ} \pm 3.63^{\circ}$ which was higher than the value obtained in present study as our subjects belonged to age group between 5-15 years. They also found the carrying angle of dominant arm to be significantly higher than non-dominant arm in both sexes which was also supported by the result of Paraskevas et al. ${ }^{15,16}$ In our study we got the higher carrying angle on the non-dominant limb than the dominant limb which was contradictory to above results.

We also studied the correlation of carrying angle left and carrying angle right with height. The mean height of male was 1.42 meters and the mean height of female was 1.30 meters. So, the height of the person with the carrying angle left showed positive correlation and the height of the person with the carrying angle right showed negative correlation. Ruparelia et al and Terra concluded that if the height of the person is less, then because of shorter lever arm, the proximal end has to angulate more in order to bring the hand in pronated position for routine work ${ }^{1,6}$. Therefore, in a shorter person the medial part of trochlear notch of ulna goes more away from the medial flange of trochlea which leads to greater carrying angle. In January 2006, Balasubramanian et al measured the carrying angle for 300 rural South Indian children aged 5-18 years and depicted that the carrying angle did not correlate well with height, weight, humeral length or ulnar length. Thus, the carrying angle of dominant limb of male was inversely proportional and that of the non-dominant limb of male and both dominant and non-dominant limb of female was found to be directly proportional with the height of a person in our present study. ${ }^{17}$

\section{CONCLUSION}

The result of the present study shows the carrying angle is greater in female than in male and it increases at the time of puberty. The carrying angle is greater in non-dominant arm than in dominant arm and the carrying angle is not inversely related to the height of the person. This study is an approach to evaluate the carrying angle in vivo for orthopedic application and the recorded measurements might be helpful in management of disorders of the elbow and its reconstruction after fractures. It is of immense help to the orthopedic surgeon for correction of cubitus varus deformity occurring after malunited supracondylor fracture of the humerus and in pediatric elbow surgery. This knowledge is also helpful in dealing with traumatic elbow injuries in childhood and adolescence and other elbow disorders that require reconstruction or arthroplasties.

\section{REFERENCES}

1. Ruparelia S, Patel S, Zalawadia A, Shah S, Patel S.V. Study of carrying angle and its correlation with various parameters. National journal of integrated research in medicine. 2010; 11(3): 0975-9840.

2. Purkait $R$, Chandra $H$. An anthropometric investigation into the probable cause of formation of carrying angle: A sex indicator. Journal of Indian academy of forensic medicine. 2004; 26(1):0971-0973.

3. Beals RK. Normal carrying angle of the elbow. Clin Orthop. 1976; 110:194-196.

4. Maria LZ, Daniela C, Sandra M, Andrea V, Maurilio M. Estimating the elbow carrying angle with an electrogoniometer. J Shoulder elbow surg 2008; 17(1):106-112

5. Khare GN, Goel SC, Saraf SK, Singh G, Mohanty C. New observations on carrying angle. Indian J Med Sci. 1999; 53:61-67.

6. Terra BB. Evolution of the carrying angle of the elbow: A clinical and radiographic study. Acta Ortop Bras. 2011; 19(2):79-82.

7. Potter HP. The obliquity of the arm of the females in extension. $J$ anat physiol. 1895:29:488-492.

8. Mall FP. On the angle of the elbow. Am J Anatomy. 1905; 4:391-404.

9. Rai J, Prakash S, Singhal V. Carrying angle in Indian boys and girls. Ind J Orthop. 1980; 14:170-174.
10. Atkinson WD, Elftman $\mathrm{H}$. The carrying angle of the human arm as a, secondary sex character. Anat Record. 1945; 91:49-53.

11. Keats TE, Teeslink R, Diamond AE, Williams JH. Normal axial relationship of the major joints. Radiol. 1966; 87:904-908.

12. Steel FLD, Tomalinson JDW. The carrying angle in man. J Anat. 1958; 92:315-317.

13. Smith L. Deformity following supracondylar fractures of the humerus. J Bone joint surg. 1960; 42-A:235-238.

14. Van RP, Baeyens JP, Fauvart D, Lanssiers R, Clarijs JP. Arthro-kinematics of the elbow: study of the carrying angle. Sports, Leisure and Ergonomics conference. 2005; 48:11-14.

15. Yilmaz E, Karakurt L, Belhan O, Bulut M, Serin E, Avci M. Variation of carrying angle with age,sex and special reference to side. Orthopedics. 2005; 28(11): 1360-1363.

16. Paraskevas G, Papadopoulos A, Papaziogas B. Study of the carrying angle of the human elbow joint in full extension: a morphometric analysis. Surgical and radiological anatomy. 2004; 26(1): 19-23.

17. Balasubramanian $P$, Madhuri V, Muliyil J. Carrying angle in children: A normative study. Journal of Pediatric orthopedics part B. 2006; 15(1):37-40. 